Received 04/18/2019

Review began 04/22/2019

Review ended 04/30/2019

Published 05/08/2019

\section{(c) Copyright 2019}

Zaarour et al. This is an open access article distributed under the terms of the Creative Commons Attribution License CC-BY 3.0., which permits unrestricted use, distribution, and reproduction in any medium, provided the original author and source are credited.

\title{
Obstructing Duodenal Diffuse Large B-cell Lymphoma with Peritoneal Lymphomatosis with Exceptional Response to R-CHOP
}

\author{
Mazen Zaarour $^{1}$, Christopher Busack ${ }^{2}$, Reinhold Munker ${ }^{1}$ \\ 1. Hematology and Oncology, Tulane University School of Medicine, New Orleans, USA 2. Internal \\ Medicine, Tulane University School of Medicine, New Orleans, USA
}

$\square$ Corresponding author: Mazen Zaarour, mfzaarour@gmail.com Disclosures can be found in Additional Information at the end of the article

\section{Abstract}

Primary small bowel tumors are uncommon and usually carry a poor prognosis.

Adenocarcinoma is the predominant histological type while lymphoma is far less common. Small bowel diffuse large B-cell lymphoma (DLBCL) can mimic adenocarcinoma; thus, the distinction can be challenging before tissue examination is performed. Bowel obstruction, as well as peritoneal involvement, are often seen in gastrointestinal (GI) adenocarcinoma cases; however, these features are extremely uncommon with GI lymphomas. Herein, the authors report an unusual case of an obstructing duodenal mass with peritoneal involvement, which was highly suspicious for an advanced duodenal adenocarcinoma. Surprisingly, sampling of the tumor revealed a diffuse large B-cell lymphoma.

Categories: Internal Medicine, Oncology

Keywords: small bowel neoplasms, gastrointestinal lymphoma, peritoneal lymphomatosis

\section{Introduction}

Primary small bowel neoplasms are rare tumors with an overall poor prognosis. The predominant histological type is adenocarcinoma. Other less common histologies include carcinoid, lymphoma, and sarcoma [1-2]. These neoplasms often have similar clinical, radiologic, and morphologic features making the distinction difficult without tissue examination.

Despite accounting for up to 40\% of cases of extranodal non-Hodgkin's lymphoma (NHL), gastrointestinal (GI) lymphoma is considered an uncommon disease [3]. Diffuse large B-cell lymphoma (DLBCL) is the predominant pathological subtype [4]. The stomach is involved in approximately half of the cases, whereas the small bowel and particularly duodenal involvement is an unusual site of disease.

Clinically, a wide range of nonspecific symptoms can be associated with small bowel lymphoma, with abdominal pain being the most common [5]. While bowel obstruction is a possible manifestation of the disease, a review of the literature favors the jejunum or the ileum as sites of the obstruction rather than the duodenum [6-7]. Furthermore, peritoneal involvement by lymphoma, known as peritoneal lymphomatosis, is less common in small bowel lymphoma [8-9].

In this report, the authors present an unusual case of small bowel obstruction secondary to a

How to cite this article

Zaarour M, Busack C, Munker R (May 08, 2019) Obstructing Duodenal Diffuse Large B-cell Lymphoma with Peritoneal Lymphomatosis with Exceptional Response to R-CHOP. Cureus 11(5): e4621. DOI 10.7759 /cureus.4621 
duodenal mass with accompanying peritoneal involvement. Surprisingly, the diagnosis was not adenocarcinoma, but DLBCL.

\section{Case Presentation}

A 40-year-old Hispanic woman was admitted to University Medical Center New Orleans, Louisiana in August 2017 for evaluation of progressively worsening abdominal pain of eight months duration with associated intermittent nausea and vomiting. The patient also reported losing approximately 30 kilograms in weight. She denied any associated fever, night sweats, change in bowel habits, rash, enlarged lumps or palpable masses. She was previously healthy and denied any personal or family history of malignancy. She never smoked and used alcohol sparingly. She had no known allergies.

On physical exam, the patient's body temperature was $98.6^{\circ} \mathrm{F}$, blood pressure was $100 / 60$ $\mathrm{mmHg}$, and heart rate was $120 / \mathrm{min}$. Cardiovascular and pulmonary exams were unremarkable. The abdomen was soft and mildly tender. A palpable mass was appreciated in the right periumbilical region. No cervical, axillary or inguinal lymphadenopathy was appreciated. Laboratory analysis showed severe metabolic derangements as follows: sodium of $121 \mathrm{mEq} / \mathrm{L}$ (reference range, $135-145 \mathrm{mEq} / \mathrm{L}$ ), potassium of $2.2 \mathrm{mEq} / \mathrm{L}$ (reference range, 3.5-5.5 mEq/L), blood urea nitrogen of $61 \mathrm{mg} / \mathrm{dL}$ (reference range, 7-20 mg/dL), and serum creatinine of 3.03 $\mathrm{mg} / \mathrm{dL}$ (reference range, $0.6-1.2 \mathrm{mg} / \mathrm{dL}$ ). Liver and pancreatic enzymes were in the normal limits. The hematologic panel was consistent with mild normocytic anemia with a hemoglobin of $11.2 \mathrm{~g} / \mathrm{dL}$ along with leukocytosis with a white blood cell count of $16.6 \times 10^{9} / \mathrm{L}$. Platelet count was normal at $299 \times 10^{9} / \mathrm{L}$. A peripheral blood smear was within normal limits. A chest radiograph was unremarkable. A non-contrast computed tomography (CT) scan of the abdomen revealed fluid-filled distention of the stomach and proximal duodenum with concern for proximal small bowel obstruction.

The patient was admitted to the intensive care unit given her various metabolic disturbances and was treated conservatively for partial small bowel obstruction. After optimization of her kidney function, a repeat scan of the abdomen with contrast was performed. An irregular masslike thickening at the level of the second/third portion of the duodenum was identified resulting in severe luminal narrowing. Also, peritoneal "carcinomatosis" with multiple target lesions was noted (Figure 1). The overall picture was concerning for metastatic carcinoma. Later, serum carcinoembryonic antigen (CEA) and Ca 19-9 levels were checked and were within normal limits. 


\section{Cureus}

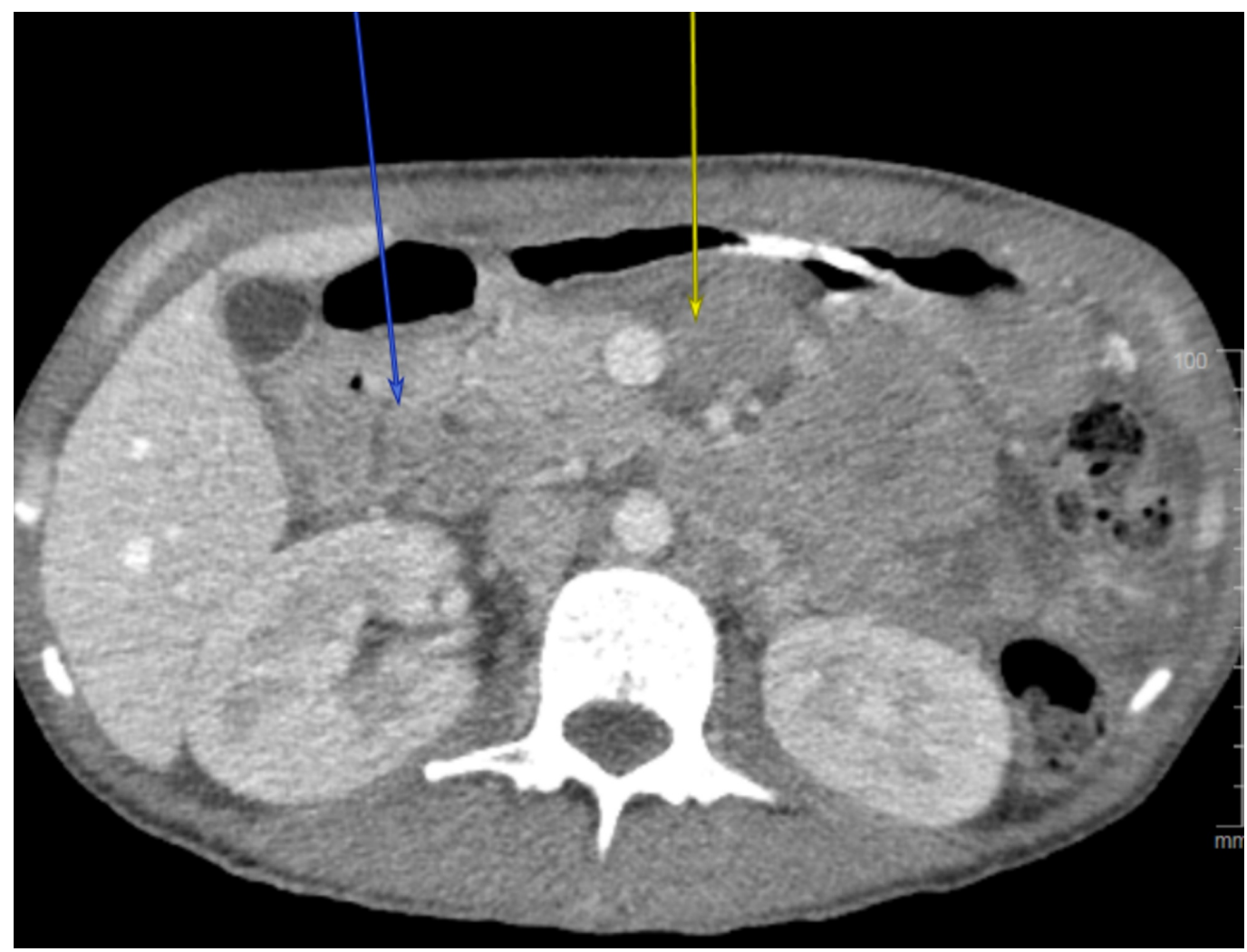

FIGURE 1: Peritoneal lymphomatosis

Computed tomography image showing multifocal masses throughout the mesentery and centered within the peritoneum, compatible with "carcinomatosis."

An upper endoscopy was performed the following day revealing a frond-like friable obstructing mass in the second portion of the duodenum of which biopsies were taken (Figure 2). Largesized lymphocytes were seen (Figure 3). 


\section{Cureus}
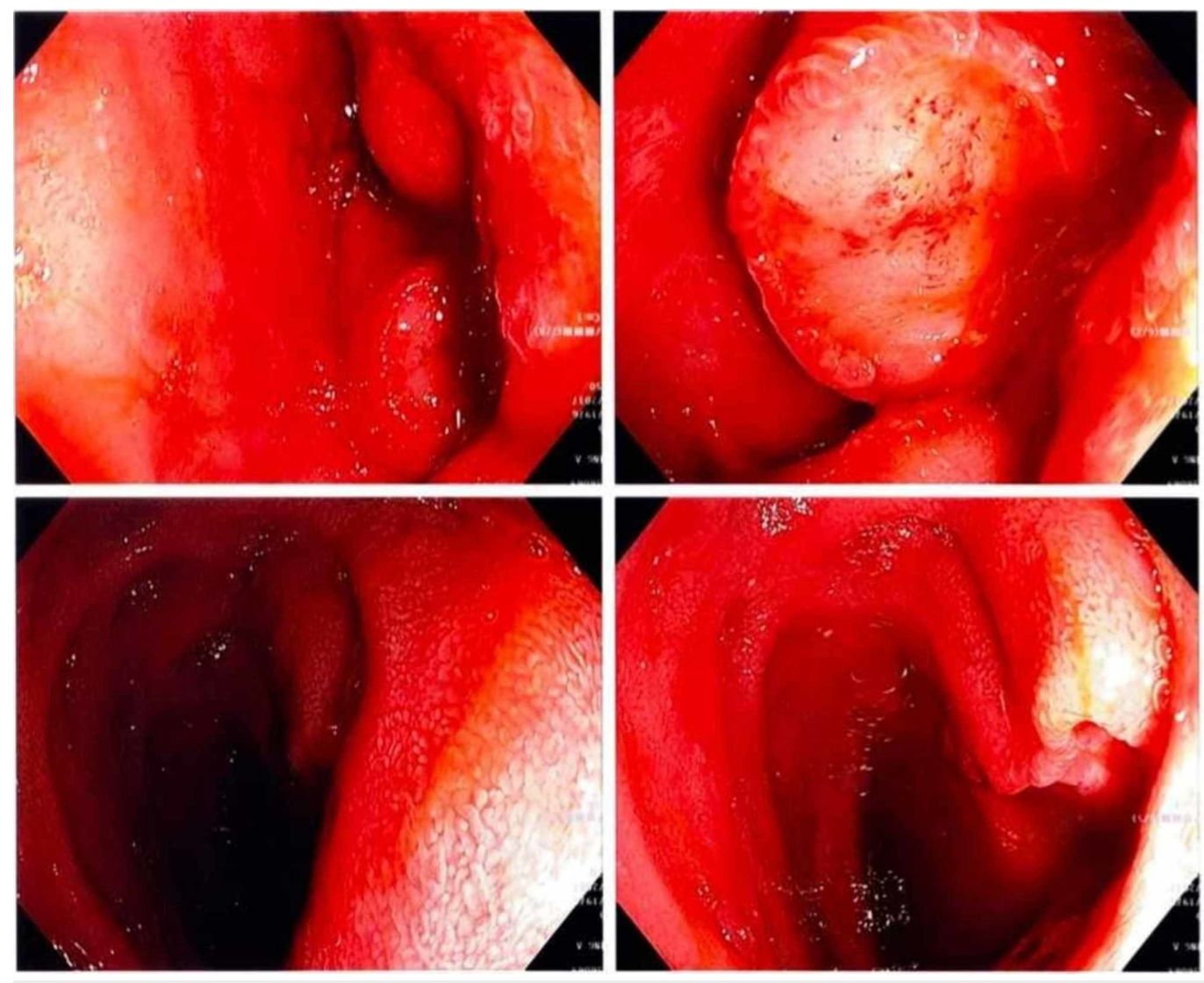

\section{FIGURE 2: Duodenal mass}

Frond-like friable obstructing mass in the second portion of the duodenum as seen from different angles on upper endoscopy. 


\section{Cureus}

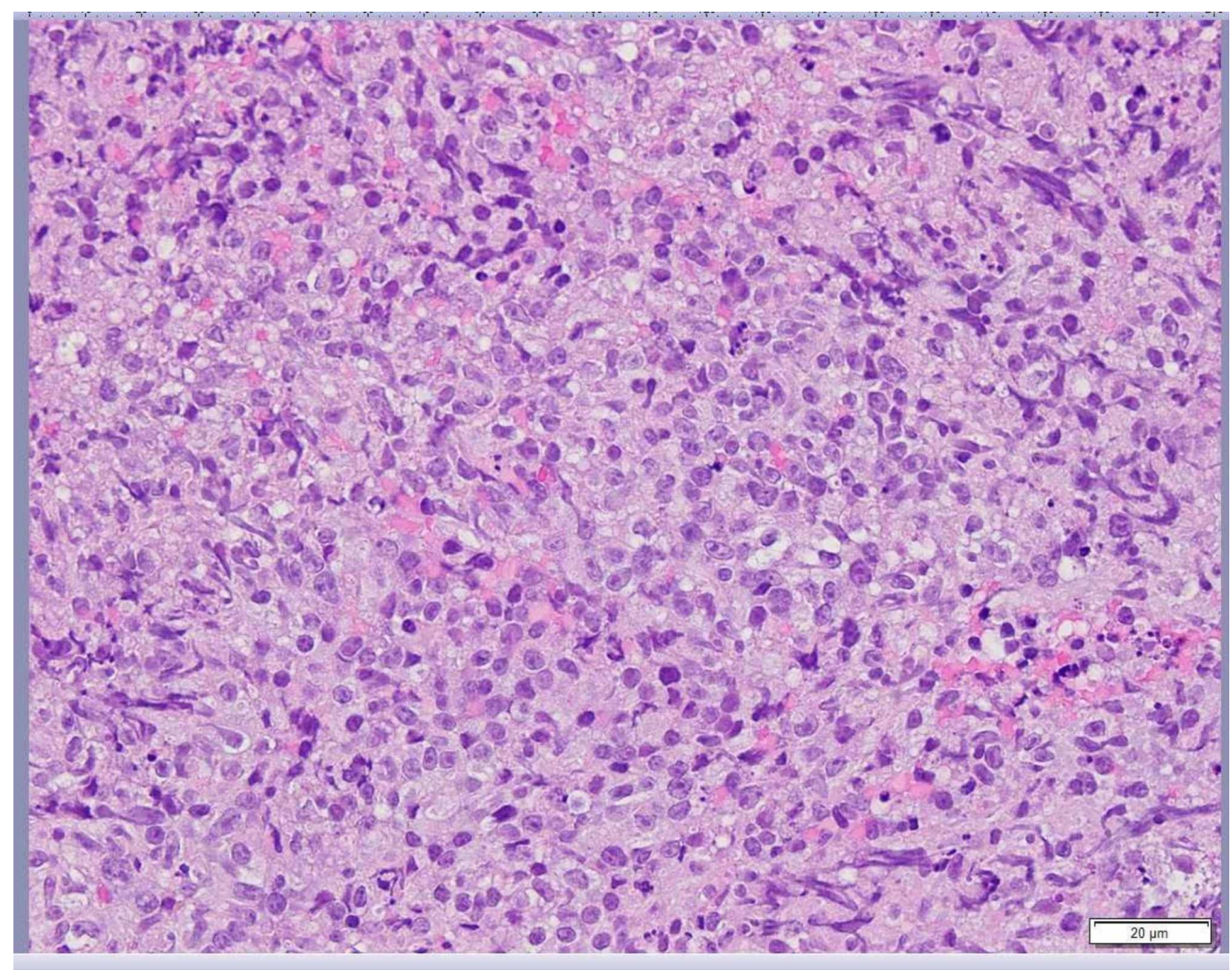

\section{FIGURE 3: Duodenal mass biopsy}

Hematoxylin and eosin stain demonstrating sheet of large-sized lymphocytes immunophenotypically consistent with diffuse large B-cell lymphoma.

Immunohistochemical stains demonstrated that these cells were strongly and diffusely positive for cluster of differentiation (CD)20 and CD79a, and negative for CD3, CD5, CD10, CD30, B-cell lymphoma 2 (Bcl-2) and pan-cytokeratin. Additionally, nuclear staining in about $40 \%$ of the neoplastic cells was present for c-Myc and in more than 30\% of cells for Bcl-6. A diagnosis of DLBCL with germinal center immunophenotype was made (CD10 negative, Bcl-6 positive, MUM-1 negative). The Ki-67 index was elevated within the B cell population at $60 \%-70 \%$. No assay specific abnormalities were detected by Bcl-2, Bcl-6, and c-Myc fluorescence in situ hybridization (FISH) probes. Completion staging with neck, chest, and pelvic CT scans failed to demonstrate any additional evidence of disease. A bone marrow examination showed no involvement by lymphoma. Human immunodeficiency virus (HIV) and hepatitis serologies were negative. Serum lactate dehydrogenase was mildly elevated at 318 U/L. Given the patient's peritoneal lymphomatosis and weight loss, she was diagnosed with stage IV B lymphoma by Ann Arbor staging.

Given the aggressive presentation with evidence of bowel obstruction and peritoneal involvement (along with markedly elevated Ki-67), the decision was made to start treatment as an inpatient. Therefore, cycle 1 of rituximab, cyclophosphamide, doxorubicin, vincristine, and prednisone (R-CHOP) was administered, and the patient tolerated the treatment well. Central nervous system (CNS) analysis and chemoprophylaxis were not performed as she was considered intermediate-risk for CNS involvement. A few days after the completion of cycle 1, she was able to tolerate oral feeding and she was discharged home. She received the remainder of her treatment as an outpatient and completed a total of six cycles of systemic chemotherapy. She exhibited significant clinical and radiographic improvement throughout her treatment. In 


\section{Cureus}

fact, a repeat scan after six cycles showed improved luminal duodenal narrowing with resolution of the peritoneal deposits (Figure 4). A push enteroscopy was also performed to assess for local response and demonstrated no evidence of disease. She remains now diseasefree 15 months after her diagnosis and 10 months after completion of her treatment.

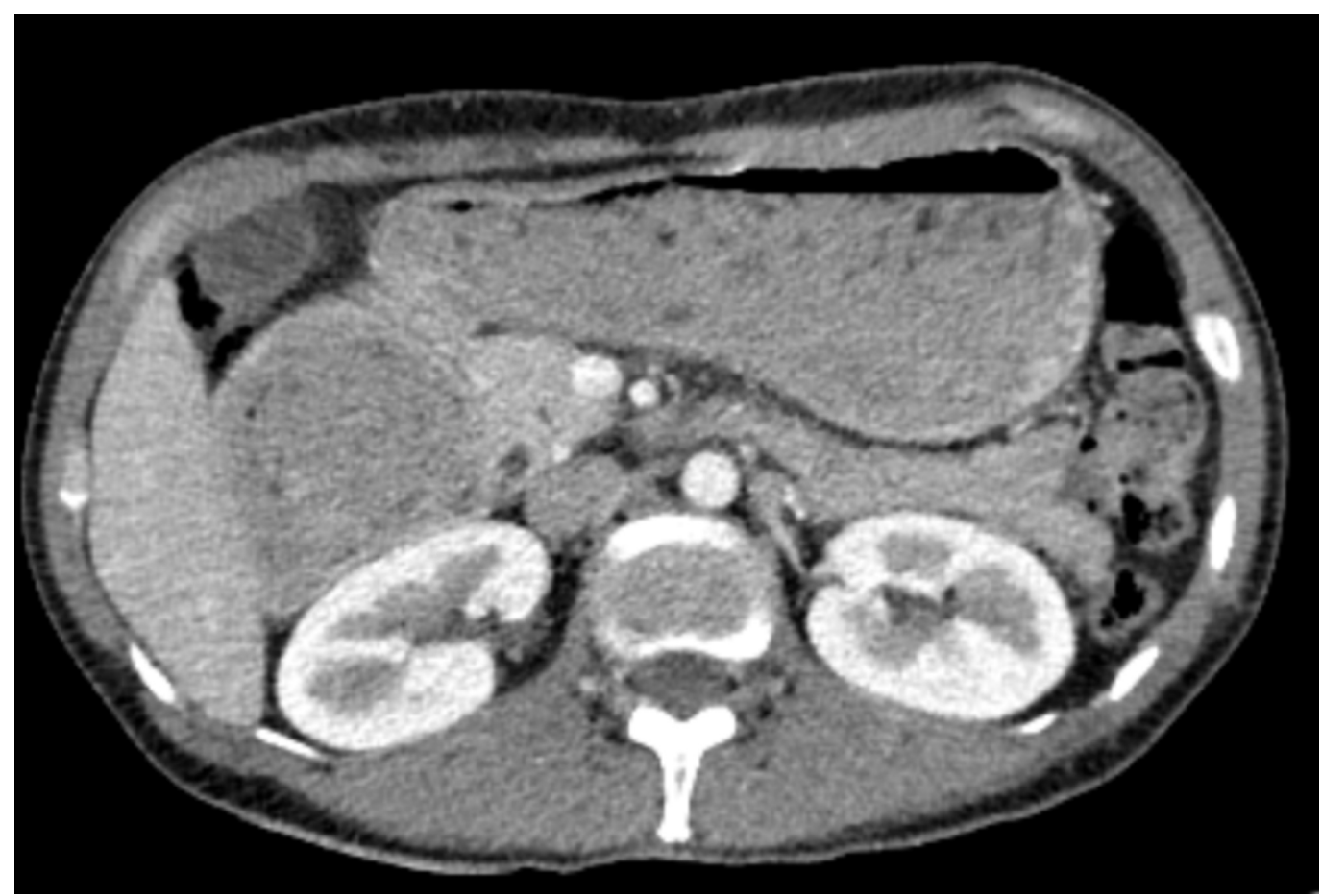

FIGURE 4: Imaging after completion of treatment

Computed tomography image showing resolution of the peritoneal carcinomatosis after 6 cycles of chemotherapy

\section{Discussion}

Primary small bowel neoplasms are rare tumors with an overall poor prognosis. Lymphomas are found in only $20 \%$ of small bowel neoplasms and tend to carry a better prognosis than small bowel adenocarcinomas [10]. However, they are more aggressive compared to other GI lymphomas, such as gastric lymphomas [11]. Due to the low incidence rate of this disease, most of the knowledge with respect to small bowel lymphoma derives from small and retrospective studies.

The GI tract is the predominant site of extranodal NHL accounting for up to $40 \%$ of cases [12]. Approximately $80 \%-90 \%$ of GI lymphomas are of B-cell origin, with DLBCL being the most common pathological subtype [4]. The pathogenesis of GI lymphomas remains unknown. Nonetheless, a number of risk factors have been implicated such as immunodeficiency syndromes, HIV, inflammatory bowel disease and post-transplant [5,7]. Half of the cases of GI lymphomas involve the stomach, and one-third of cases involve the small bowel [4]. In numerous reports of patients with primary intestinal NHL, the ileum was the most common primary site, followed by the jejunum and the duodenum $[4,13]$. This distribution parallels that of lymphoid tissue in the different segments of the small bowel. Of special interest, duodenal lymphomas are extremely rare, occurring in < 2\% of all GI lymphomas [14-15] and less than 20\% of intestinal NHL $[4,13]$. 
A wide range of nonspecific clinical symptoms has been reported with intestinal lymphomas. Abdominal pain is the main presenting symptom, and B symptoms are not commonly seen [7]. Bowel obstruction is a common disease manifestation, reported in almost $40 \%$ of patients with intestinal NHL in one series [5]. The patient described in this report presented with bowel obstruction secondary to a duodenal tumor. This seems to be an unusual site of obstruction for DLBCL. In fact, not a single case of duodenal obstruction was identified among patients with GI lymphoma and bowel obstruction reported in two cases from Turkey by Karadeli et al. [6] and Avci et al. [7].

Peritoneal involvement can be seen with cases of GI adenocarcinoma, known as peritoneal carcinomatosis. Peritoneal involvement by lymphoma, known as lymphomatosis, is extremely uncommon [8-9]. These two entities are indistinguishable by imaging only. Peritoneal lymphomatosis is thought to be associated with aggressive histological subtypes [16]. Our patient developed bowel obstruction secondary to an intraluminal tumor and was found to have evidence of peritoneal involvement. This presentation was highly concerning for an adenocarcinoma, the most common small bowel tumor which is also well known for peritoneal dissemination. Surprisingly, a lymphoma was diagnosed after tissue examination. GI lymphomas, despite being less common, can closely mimic their adenocarcinoma counterparts and should remain in the differential diagnosis of tumors causing bowel obstruction with peritoneal involvement.

Due to the low incidence of intestinal DLBCL, the optimal treatment remains unknown. Options in the form of surgery alone, surgery followed by systemic chemotherapy, chemotherapy alone, or radiation alone have been reported in the literature [11,13]. Surgery was historically considered the mainstay of treatment. However, since lymphomas are highly chemosensitive, resection is rarely used presently unless in circumstances of palliative intent or for management of complications from the disease like perforation or severe bleeding. The most commonly used chemotherapy regimen is CHOP with rituximab. The patient presented in this report was treated with the conventional R-CHOP regimen for a total of six cycles, which led to complete remission. This response is consistent with other reports of patients with duodenal DLBCL treated with the same regimen [17-18].

\section{Conclusions}

DLBCL presenting as a duodenal mass and resulting in small bowel obstruction is a rare occurrence. Moreover, peritoneal involvement by lymphoma is extremely uncommon and remains a major diagnostic challenge to physicians. Therefore, despite being less common than adenocarcinoma, lymphoma should always remain in the differential diagnosis of GI tumors with or without peritoneal spread.

\section{Additional Information \\ Disclosures}

Human subjects: Consent was obtained by all participants in this study. Conflicts of interest: In compliance with the ICMJE uniform disclosure form, all authors declare the following:

Payment/services info: All authors have declared that no financial support was received from any organization for the submitted work. Financial relationships: All authors have declared that they have no financial relationships at present or within the previous three years with any organizations that might have an interest in the submitted work. Other relationships: All authors have declared that there are no other relationships or activities that could appear to have influenced the submitted work.

\section{References}


1. Terada T: Malignant tumors of the small intestine: a histopathologic study of 41 cases among 1,312 consecutive specimens of small intestine. Int J Clin Exp Pathol. 2012, 5:203-9.

2. Wang Z, Ding Z, Huang S, Zhong S: Experience in clinical diagnosis and treatment of duodenal tumors. Mol Clin Oncol. 2016, 5:731-739. 10.3892/mco.2016.1061

3. Freeman C, Berg JW, Cutler SJ: Occurrence and prognosis of extranodal lymphomas . Cancer. 1972, 29:252-60.

4. Li B, Shi YK, He XH, et al.: Primary non-Hodgkin lymphomas in the small and large intestine: clinicopathological characteristics and management of 40 patients. Int J Hematol. 2008, 87:375-381. 10.1007/s12185-008-0068-5

5. Yin L, Chen CQ, Peng CH, et al.: Primary small-bowel non-Hodgkin's lymphoma: a study of clinical features, pathology, management and prognosis. J Int Med Res. 2007, 35:406-15. 10.1177/147323000703500316

6. Karadeli E, Erbay G, Parlakgumus A, Yabanoglu H: Abdominal CT findings in patients with primary lymphoma causing small bowel obstruction. J Coll Physicians Surg Pak. 2017, 27:711713.

7. Avcı T, Yabanoğlu H, Arer İM, Koçer EM, Çalışkan K, Böcek P, Ekici Y: Primary small intestinal non-Hodgkin lymphoma diagnosed after emergency surgery [Article in English, Turkish]. Ulus Travma Acil Cerrahi Derg. 2017, 23:128-133. 10.5505/tjtes.2016.02359

8. Horger M, Müller-Schimpfle M, Yirkin I, Wehrmann M, Claussen CD: Extensive peritoneal and omental lymphomatosis with raised CA 125 mimicking carcinomatosis: CT and intraoperative findings. Br J Radiol. 2004, 77:71-3. 10.1259/bjr/35139284

9. Kim YG, Baek JY, Kim SY, et al.: Peritoneal lymphomatosis confounded by prior history of colon cancer: a case report. BMC Cancer. 2011, 11:276. 10.1186/1471-2407-11-276

10. Koch P, del Valle F, Berdel WE, et al.: Primary gastrointestinal non-Hodgkin's lymphoma: II. Combined surgical and conservative or conservative management only in localized gastric lymphoma--results of the prospective German Multicenter Study GIT NHL 01/92. J Clin Oncol. 2001, 19:3874-83. 10.1200/JCO.2001.19.18.3874

11. Lightner AL, Shannon E, Gibbons MM, Russell CM: Primary gastrointestinal non-Hodgkin's lymphoma of the small and large intestines: a systematic review. J Gastrointest Surg. 2016, 20:827-39. 10.1007/s11605-015-3052-4

12. Freeman C, Berg JW, Cutler SJ: Occurrence and prognosis of extranodal lymphomas . Cancer. 1972, 29:252-60.

13. Ge Z, Liu Z, Hu X: Anatomic distribution, clinical features, and survival data of 87 cases primary gastrointestinal lymphoma. World J Surg Oncol. 2016, 14:85. 10.1186/s12957-0160821-9

14. Cirillo M, Federico M, Curci G, Tamborrino E, Piccinini L, Silingardi V: Primary gastrointestinal lymphoma: a clinicopathological study of 58 cases. Haematologica. 1992, 77:156-61.

15. Domizio P, Owen RA, Shepherd NA, Talbot IC, Norton AJ: Primary lymphoma of the small intestine. A clinicopathological study of 119 cases. Am J Surg Pathol. 1993, 17:429-42.

16. Curakova E, Genadieva-Dimitrova M, Misevski J, et al.: Nonhodgkin's lymphoma with peritoneal localization. Case Rep Gastrointest Med. 2014, 2014:723473. 10.1155/2014/723473

17. Morishita A, Mori H, Kobara H, et al.: Successful mucosal incision-assisted biopsy for the histological diagnosis of duodenal lymphoma: a case report. Oncol Lett. 2016, 11:531-534. 10.3892/ol.2015.3973

18. Kröner PT, Mankal PK, Elhaddad A, Shi W, Abed J, Paik J, Kotler D: Primary small-bowel diffuse large B-cell lymphoma presenting as hematemesis. Endoscopy. 2015, 47:E526-E528. $10.1055 / \mathrm{s}-0034-1392874$ 